\title{
Identification of SNPs associated with magnesium and sodium uptake and the effect of their accumulation on micro and macro nutrient levels in Vitis vinifera
}

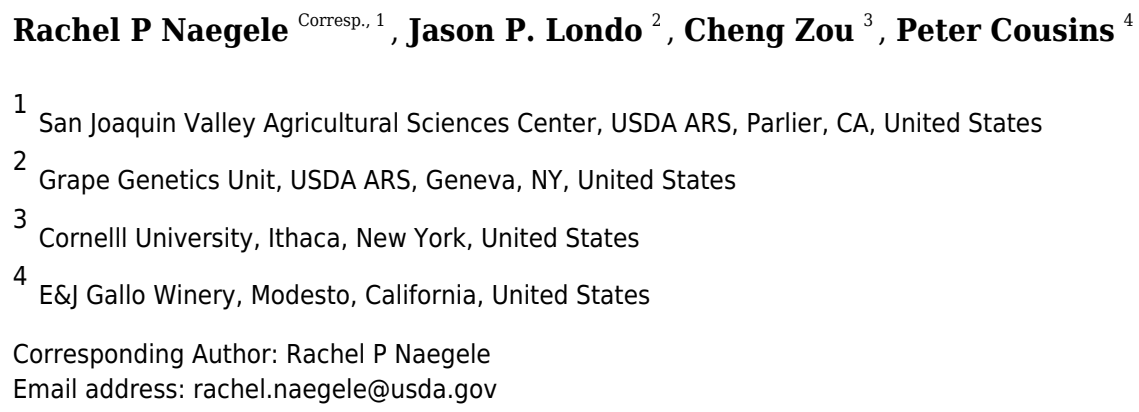

Macro and micro nutrient accumulation affects all stages of plant growth and development. When nutrient deficiencies or excesses occur, normal plant growth is altered resulting in symptoms such as leaf chlorosis, plant stunting or death. In grapes, few genomic regions associated with nutrient accumulation or deficiencies have been identified. Our study evaluated micro and macro nutrient concentrations in Vitis vinifera L. to identify associated SNPs using an association approach with genotype by sequencing data. Nutrient concentrations and foliar symptoms (leaf chlorosis and stunting) were compared among $249 F_{1}$ Vitis vinifera individuals in 2015 and 2016. Foliar symptoms were consistent $(\geq 90 \%$ ) between years and correlated with changes in nutrient concentrations of magnesium ( $r=0.65$ and $r=0.38$ in 2015 and 2016, respectively), aluminum ( $r=0.24$ and $r=0.49)$, iron $(r=0.21$ and $r=0.49)$, and sodium $(r=0.32$ and $r=0.21)$. Single nucleotide polymorphisms associated with symptoms, sodium, and magnesium were detected on each chromosome with the exception of 5, 7 and 17 depending on the trait and genome used for analyses explaining up to $40 \%$ of the observed variation. Symptoms and magnesium concentration were primarily associated with SNPs on chromosome 3, while SNPs associated with increased sodium content were primarily found on chromosomes 11 and 18. Mean concentrations for each nutrient varied between years in the population between symptomatic and asymptomatic plants, but relative relationships were mostly consistent. These data suggest a complex relationship among foliar symptoms and micro and macro nutrients accumulating in grapevines. 
Identification of SNPs associated with magnesium and sodium uptake and the effect of their accumulation on micro and macro nutrient levels in Vitis vinifera

Rachel P. Naegele ${ }^{1}$, Jason P. Londo ${ }^{2}$, Cheng Zou ${ }^{3}$ and Peter Cousins ${ }^{4}$

${ }^{1}$ USDA ARS San Joaquin Valley Agricultural Sciences Center Parlier, CA 93648

${ }^{2}$ USDA ARS Grape Genetics Unit Geneva, NY

${ }^{3}$ Cornell University, Ithaca, NY

${ }^{4}$ E\&J Gallo Winery, Modesto, CA

Corresponding Author:

Rachel Naegele

9611 S. Riverbend Ave Parlier, CA 93648

Email address: Rachel.naegele@usda.gov 


\section{Abstract}

2

3 Macro and micro nutrient accumulation affects all stages of plant growth and development.

4 When nutrient deficiencies or excesses occur, normal plant growth is altered resulting in

5 symptoms such as leaf chlorosis, plant stunting or death. In grapes, few genomic regions

6 associated with nutrient accumulation or deficiencies have been identified. Our study evaluated

7 micro and macro nutrient concentrations in Vitis vinifera L. to identify associated SNPs using an

8 association approach with genotype by sequencing data. Nutrient concentrations and foliar

9 symptoms (leaf chlorosis and stunting) were compared among $249 \mathrm{~F}_{1}$ Vitis vinifera individuals in 102015 and 2016. Foliar symptoms were consistent $(\geq 90 \%)$ between years and correlated with 11 changes in nutrient concentrations of magnesium $(r=0.65$ and $r=0.38$ in 2015 and 2016,

12 respectively), aluminum $(r=0.24$ and $r=0.49)$, iron $(r=0.21$ and $r=0.49)$, and sodium $(r=0.32$ 13 and $\mathrm{r}=0.21$ ). Single nucleotide polymorphisms associated with symptoms, sodium, and 14 magnesium were detected on each chromosome with the exception of 5, 7 and 17 depending on 15 the trait and genome used for analyses explaining up to $40 \%$ of the observed variation.

16 Symptoms and magnesium concentration were primarily associated with SNPs on chromosome 17 3, while SNPs associated with increased sodium content were primarily found on chromosomes

1811 and 18. Mean concentrations for each nutrient varied between years in the population between 19 symptomatic and asymptomatic plants, but relative relationships were mostly consistent. These 20 data suggest a complex relationship among foliar symptoms and micro and macro nutrients 21 accumulating in grapevines. 


\section{Introduction}

24

25 Macro and micronutrients are essential for proper cell function and overall plant health.

26 Macronutrients, those needed in large quantities by plants, include nitrogen, phosphorus,

27 potassium, calcium, sulfur, and magnesium. These are largely present in the soil and are readily

28 available to plants depending on soil $\mathrm{pH}$ and moisture (Maathuis 2009). Micronutrients, such as

29 sodium, boron, iron, zinc, manganese and copper, are less prevalent in the soil, but small

30 quantities are still necessary for plant growth and development. Nutrient levels fluctuate in the

31 plant, and vary based on developmental stage, maturity, genotype, and tissue (Benito et al. 2013;

32 Pradubsuk and Davenport 2010).

33

34 Nutrient deficiencies often result from poor ion availability or uptake, leading to deformation of

35 shoots or roots, uneven ripening of fruit, and chlorosis or necrosis of leaves. Leaf chlorosis is a

36 common symptom of nutrient deficiency, as many macro and micronutrients contribute to

37 chlorophyll production, enzyme and membrane stabilization and activation. Magnesium $(\mathrm{Mg})$ is

38 an important structural component of chlorophyll and a phosphorylizer or dephosphorilizer of

39 compounds. Symptoms of Mg deficiency, such as interveinal chlorosis of the leaves, necrotic

40 leaf spots, and root and shoot stunting can be induced by low levels of $\mathrm{Mg}$ or high levels of

41 calcium $(\mathrm{Ca})$, potassium $(\mathrm{K})$ or other ions, which can alter Mg absorption (Guo et al. 2016;

42 Hermans and Verbruggen 2005; Skinner and Matthews 1990; Spiers and Braswell 1994).

43

44 Sodium $(\mathrm{Na})$ can be used by plants in small quantities, but in excess, causes stunting, leaf tip

45 burning, and leaf darkening (Bernstein 1975). Leaf chlorosis, found in many nutrient

46 deficiencies, is not a characteristic symptom of $\mathrm{Na}$ excess, except as a result of cation

47 imbalances. These imbalances can be the result of substrate competition, as is the case with $\mathrm{Mg}$,

$48 \mathrm{~K}$ and $\mathrm{Ca}$, or can occur through changes in ion potential and turgor pressure (Grattan and Grieve

49 1992; Zhu et al. 1998). This complex relationship, while not well studied, varies among host

50 species and type of salt ions (Carbonell-Barrachina et al. 2008; Cordovilla et al. 2008; Volkmar

51 et al. 1998). Complex relationships are also true among metal ions and nutrients in the soil.

52 Aluminum (Al), a highly abundant metal in earth's crust, is one of the major factors limiting crop

53 production in low pH soils (Mossor-Petraszewska 2001). Aluminum competes with other ions 
54 such as $\mathrm{Mg}$ or $\mathrm{Ca}$ for binding sites in the plant, leading to root deformation and nutrient

55 deficiencies. It is often the lack of essential nutrients, and not the accumulation of toxic metals,

56 that results in metal toxicity symptoms.

57

58 In grape, a perennial woody vine, nutrient fluctuations occur throughout the season with specific

59 nutrient concentrations peaking during critical periods of development and growth. The

60 composition and quantities of these nutrients can have drastic effects on fruit quality and plant

61 health pre and postharvest (Conradie 1981; Conradie 1992; Morris et al. 1983; Mpelasoka et al.

62 2003; Rogiers et al. 2000; Schreiner 2016; Williams et al. 2004). In cultivated grape, Vitis

63 vinifera, nutrient deficiencies are commonly observed in poor quality soils and can affect bud

64 development, fruit yield, and quality (Brancadoro et al. 1995; Sinilal et al. 2011; Tagliavini and

65 Rombola 2001). Fe and Mg are two of the most common deficiencies observed in grape, often

66 observed as interveinal chlorosis (Brancadoro et al. 1995; Conradie and Saayman 1989).

67 Common nutrient excesses include Na and K (Downtown 1977; Gong et al. 2015), though the

68 severity of response can vary greatly depending on the genotype used and level of excess (Kocsis

69 and Walker 2003; Porro et al. 2013). However, foliar symptoms may also be the result of

70 interactions among nutrients, and this has not been well-studied (Shikhamany et al. 1988;

71 Skinner and Matthews 1990). Skinner and Mathews (1990) found that adding phosphorous to the

72 soil eliminated $\mathrm{Mg}$ deficiency symptoms and increased overall $\mathrm{Mg}$ concentrations.

73

74 Genotypic variation in nutrient levels is often caused by differences in the ability of a plant to

75 uptake, accumulate, or metabolize nutrients (Christensen 1984). Studies on the genetic control

76 of nutrient accumulation in grape are limited, those that exist merely show the complexity

77 surrounding nutrient absorption and their interactions (Davies et al. 2006; Jimenez et al. 2007;

78 Perez-Castro et al. 2012; Primikirios and Roubelakis-Angelakis 2001). QTL analyses have

79 identified regions associated with $\mathrm{Fe}$ and $\mathrm{Na}$ tolerance and $\mathrm{Mg}$ deficiency. For Fe tolerance, a

80 major QTL located on chromosome 13 explained up to $50 \%$ of the phenotypic variation in root

81 and shoot biomass over two years using a Vitis inter-specific cross between Cabernet Sauvignon

82 ( . vinifera) and Gloire de Montpellier ( $V$. riparia) under chlorosing conditions. Minor effect

83 QTL were also detected on chromosomes 5, 9, 18, 19 with variation evident between years (Bert

84 et al. 2013). Two QTL on chromosomes 11 and 13 were associated with Fe concentration in 
85 grafted plants only. An interspecific-hybrid population between two rootstocks was evaluated for

86 leaf sodium exclusion. Na leaf concentrations were found to be associated with a block of 538

87 genes located on chromosome 11 explaining $72 \%$ of the variation (Henderson et al. 2018). The

88 authors characterized the proteins from four different alleles of high-affinity potassium

89 transporters, and found allelic variants affected $\mathrm{Na}$ accumulation. For $\mathrm{Mg}$ deficiency, leaf

90 symptoms and $\mathrm{Mg}$ concentrations were negatively correlated $(\mathrm{r}=-0.52)$, and it was determined

91 that deficiency was controlled by a major QTL accounting for approximately $55 \%$ of the

92 variation located on linkage group 11 (Mandl et al. 2006). Based on unstable inheritance in later

93 generations, it was postulated that highly symptomatic plants were the result of an interaction

94 between alleles from both progenitors. However, this study did not evaluate the levels of other

95 elements such as $\mathrm{P}, \mathrm{K}$, and $\mathrm{Ca}$ which are known to affect $\mathrm{Mg}$ absorption and allocation. Each of

96 these studies identified QTL using inter-specific crosses.

97

98 In grape, few studies have examined the genetics of nutrient absorption and concentrations and

99 its relationship to phenotypic variation despite importance in plant development and fruit quality.

100 Mapping families remain a useful tool for understanding the genetic architecture of complex

101 traits, such as nutrient balance, and we observed symptoms initially believed to be Mg over-

102 accumulation in an $\mathrm{F}_{1}$ breeding population derived from a cross between two $V$. vinifera

103 cultivars, 'Verdejo' and 'Gewurztraminer'. Leveraging the structure of this $\mathrm{F}_{1}$ population, the

104 objectives of this study were to determine the relationship between nutrients and visible

105 symptoms, heritability and segregation, identify genomic regions associated with magnesium,

106 sodium, and other macro and micro nutrients accumulation in Vitis vinifera L., and compare SNP

107 detection across two reference genomes.

108

109 Materials and Methods

110 Material and nutrient analyses

111 Two hundred forty-nine seedlings of a segregating Vitis vinifera $\mathrm{F}_{1}$ breeding population derived

112 from two heterozygous grape varieties, 'Verdejo' x 'Gewürztraminer' (VxT) were transplanted

113 in June 2013 into a research plot in Ripperdan, CA (soil type = Cajon loamy sand, Dinuba-El

114 Peco fine sandy loam, Pachappa sandy loam, slightly - moderately saline-alkali; $\mathrm{pH}=7.9$ ). All

115 vines were own rooted with no grafting. Row spacing was set at $1.22 \mathrm{~m}$ with $2.44 \mathrm{~m}$ between

Peer] reviewing PDF | (2019:08:40548:4:0:NEW 17 Dec 2020) 
116 rows. Seedlings were trained and managed according to standard grower practices. Plants were

117 fertilized with $\mathrm{N}, \mathrm{P}$, and $\mathrm{K}$ at rates of 14.5, 18.4, and $12.9 \mathrm{~kg} /$ hectare, respectively in 2015 and

$11818.1,23.1$, and $16.1 \mathrm{~kg} /$ hectare in 2016. Fertilization was performed according to industry

119 standard practices; fertigation by applying a liquid fertilizer solution through the drip irrigation

120 every two weeks from the time of fruit set. Lateral shoots were removed from the trunk during

121 establishment and vines were trained to a unilateral cordon and spur-pruned. Plants were visually

122 assessed for foliar symptoms in August (2015) and September (2016) using a 1 (present) or 0

123 (absence) rating where symptoms were plant stunting and/or leaf chlorosis (Figure 1). Plant

124 stunting and leaf chlorosis were evaluated separately. For nutrient analysis fully expanded whole

125 leaf (petiole and blade) samples were collected from each vine. Due to variability between

126 genotypes, equivalent leaf volume was collected, typically between 15-25 mature leaves. The

127 leaves were sampled from fertile (fruiting) shoots into brown paper bags and air dried indoors at

$12822{ }^{\circ} \mathrm{C}$. Once dry, the leaves were submitted to A \& L's Western Labs (Modesto, CA) for

129 nutrient analyses in October 2015 and in October 2016. Nutrient concentrations were measured

130 for nitrogen $(\mathrm{N})$, sulfur $(\mathrm{S})$, phosphorus $(\mathrm{P})$, potassium $(\mathrm{K})$, magnesium $(\mathrm{Mg})$, calcium $(\mathrm{Ca})$,

131 sodium $(\mathrm{Na})$, iron $(\mathrm{Fe})$, aluminum $(\mathrm{Al})$, manganese $(\mathrm{Mn})$, boron $(\mathrm{B})$, copper $(\mathrm{Cu})$, and zinc $(\mathrm{Zn})$.

$132 \mathrm{~N}$ was measured using automated combustion at $900^{\circ} \mathrm{C} . \mathrm{S}, \mathrm{P}, \mathrm{K}, \mathrm{Mn}, \mathrm{Ca}, \mathrm{Na}, \mathrm{Fe}, \mathrm{Al}, \mathrm{Mg}, \mathrm{B}, \mathrm{Cu}$

133 and $\mathrm{Zn}$ were measured using nitric/hydrochloric acid digestion using a microwave, analysis was

134 by inductively coupled plasma spectrometry (ICP) as detailed by The North American

135 Proficiency Testing Program (Black, 1965; naptprogram.org). N, S, P, K, Mg, Ca, and Na were

136 reported as a percent of dry matter $(\% \mathrm{dm})$. Fe, $\mathrm{Al}, \mathrm{Mn}, \mathrm{B}, \mathrm{Cu}$ and $\mathrm{Zn}$ were reported as parts per

137 million (ppm). At the end of the study, a subset of symptomatic and asymptomatic vines was

138 removed and evaluated for root stunting.

139

$140 \quad$ Statistical analysis

141 Nutrient data were analyzed using JMP v12 statistical software (SAS Institute, Cary, NC) for

142 normality (Shapiro-Wilk W Test), analysis of variance (ANOVA), hierarchical clustering, and

143 correlations for relationships within and between years. Plant symptoms were analyzed as

144 marginal chlorosis only, stunting only, or combined (stunting and/or chlorosis). Data for $\mathrm{Zn}, \mathrm{Na}$,

$145 \mathrm{P}$, and Mn were log transformed, $\mathrm{S}, \mathrm{Mg}, \mathrm{Fe}, \mathrm{B}$, and $\mathrm{Al}$ were $\log 10$ transformed, and $\mathrm{Ca}$ and $\mathrm{K}$

146 were square root transformed to fulfill assumptions of normality. Significant differences in 
147 nutrient concentrations between years or genotypes were determined using Tukey's Honest

148 Significant Difference (HSD) ( $\mathrm{P} \geq 0.05)$. Correlations were determined using Pearson's

149 correlation coefficient ( $r$ ) on the transformed data. Hierarchical clustering was determined using

150 the Ward method on standardized data. Broad sense heritability $(\mathrm{H})$ was calculated based on

151 mean square values using the one location across two years formula modified from Fehr (1987)

152 by Wang et al. (2000) with confidence intervals estimated by Knapp et al. (1985). Best Linear

153 Unbiased Predictors (BLUPs) were calculated with the lme4 package in R (v4.0.2 R Core

154 Development Team, 2017) using nutrient concentration, genotype, and year as random effects

155 (Henderson, 1975; Liu et al, 2008; Merk, 2011). Principal component analysis for the population

156 was calculated using the BLUPs for each nutrient concentration within JMP12.0.1.

157

158 Genotyping by sequencing and mapping of significant SNP associations

159 Young grape leaves were collected from each $F_{1}$ progeny grapevine in July 2015 and genomic

160 DNA extracted using the Qiagen genomic DNA extraction kit (Qiagen, Inc Valencia, CA).

161 Genomic DNA was sent to the UC Davis Genome Center's DNA Technologies and Expression

162 Analysis Cores (University of California, Davis) for quality analysis, restriction enzyme

163 digestion (ApeK1), library preparation and Illumina Hi-seq 3000 sequencing. Sequencing

164 coverage was approximately 2.7 million reads per sample. Genotyping by sequencing (GBS)

165 data was analyzed using the Tassel 5.0 GBSv2 pipeline (Bradbury et al. 2007). The table

166 grape/raisin genome of Thompson Seedless was used, in addition to the wine grape-derived

167 inbred genome of PN40024, to capture some of the variability in SNP detection between

168 reference genomes. Quality $(\leq 20)$ and length $(\geq 20 \mathrm{bp})$ filtered and trimmed reads were aligned

169 to the Thompson Seedless genome (Genova et al. 2014; Patel et al. 2018) and the PN40024

170 12xv2 genome (Canaguier et al., 2017) using BWA (Li and Durbin 2010). Identified SNPs were

171 further filtered for frequency of minor $(0.20)$ and major $(\geq 0.35)$ allele frequencies, missing data

$172(\leq 10 \%)$, and sequencing depth $(\geq 5$ reads (Thompson Seedless or $\geq 10$ reads (PN40024)) using

173 vcftools 0.1.15 (Danecek et al. 2011). For the PN40024 genome, an additional filtering step to

174 thin SNPs based on physical position to a minimum of $50 \mathrm{bp}$ between sites was completed. A

175 panel of 10,122 and 3,997 filtered SNPs (Thompson Seedless and PN40024, respectively) were

176 used for genome-wide association analyses for each of the ions measured (Table 1). A kinship

177 matrix was estimated in Tassel v 5.2.43 and used in a MLM (mixed linear model) implemented 
178 in the software GAPIT v2 for nutrient trait analyses within R statistical analysis software (Lipka 179 et al. 2012; Tang et al. 2016, R Core Development Team, 2017). For binary traits (stunting, 180 chlorosis, and combined symptoms), 2 principal components with P3D were used for analyses 181 implemented within Tassel. Significance of a SNP was based on a $P$ value $\leq 0.05$ and a false 182 discovery rate $($ FDR $) \leq 0.05$. Linkage decay was estimated using PopLDdecay for the PN40024 183 genome (Zhang et al. 2019). In brief, pairwise $\mathrm{r}^{2}$ for SNPs within $5 \mathrm{Mb}$ were calculated using 184 PopLDdecay, then the median $\mathrm{r}^{2}$ for every $10 \mathrm{~kb}$ window were calculated (Zhang et al. 2019).

185 The continuity of the Thompson Seedless genome is of lower quality than that of PN40024. Thus 186 to cross reference significant SNPs detected in each reference genome, PN40024 was used as a 187 coordinate reference. GBS tags with significant SNPs detected in Thompson seedless and their 188 associated flanking sequence were mapped back to PN40024 to unify coordinates. Sequences 189 were mapped using default parameters for short read alignment using Minimap2 (Li 2018).

190 Uniquely mapped primary alignments with quality higher than 40 were kept in the lift-over.

191 Manhattan plots for chromosome 3 were produced using the CMplot package in $\mathrm{R}$

192 (https://github.com/YinLiLin/R-CMplot).This method allowed for the ordering of SNPs in the 193 same coordinate reference and comparison between distributions.

195 Functional annotation of genes associated with SNPs was determined using Blast2GO v 5.2.5

196 based on the nonredundant database from NCBI, and protein databases from Uniprot and 197 Swissprot (Gotz et al., 2008; accessed June 2018).

198

199

\section{Results}

200

\section{$201 \quad$ Field symptoms}

202 There were 60 and 52 individual vines exhibiting symptoms, while 189 and 197 did not exhibit 203 symptoms in 2015 and 2016, respectively, roughly following a 3:1 segregation. The parents, not 204 grown at the time of this study, had not previously displayed any symptoms of nutrient 205 imbalances at this location under similar fertilization regimes. Symptoms observed in the $F_{1}$ 206 progeny included leaf, internode, and petiole stunting, as well as marginal leaf chlorosis and 207 necrosis (Fig 1). A subset of symptomatic and asymptomatic plants evaluated for root stunting 208 showed no visible differences (data not shown). Presence of symptoms (stunting or chlorosis) 
209 was consistent between 2015 and 2016 for most vines (>90\%). Only eighteen vines had

210 symptoms in 2015, but were asymptomatic in 2016. Another two genotypes had no symptoms in

2112015 , but were symptomatic in 2016. When each symptom was evaluated individually, stunting

212 and marginal chlorosis symptoms were consistent among plants in both years $(>80 \%)$.

213

214 Nutrient compilation

215 For the population, significant differences were detected in nutrient concentrations between 2015

216 and 2016 (Table 2). Large increases in $\mathrm{Al}, \mathrm{Fe}, \mathrm{Mg}, \mathrm{Zn}, \mathrm{Mn}$ and $\mathrm{Ca}$ concentrations were observed

217 in leaf tissue between samples collected in 2015 and 2016. Mean values for nutrient

218 concentrations varied for most of the ions evaluated among individuals in the VxT population

219 (Supplemental Figure 1, Supplemental Table 1). A decrease in N, P, K, and B leaf nutrient

220 concentrations was observed from 2015 to 2016 . When symptomatic and asymptomatic plants

221 were analyzed separately, differences in nutrient concentration were detected in 2015 and 2016

222 (Table 3). Higher levels of $\mathrm{Mg}, \mathrm{Na}, \mathrm{Al}$, and Fe were observed in symptomatic plants in both

223 years, while a decrease in $\mathrm{N}$ was observed. $\mathrm{Na}, \mathrm{P}, \mathrm{Cu}, \mathrm{Mn}, \mathrm{N}, \mathrm{S}$, and Ca concentrations in 2015

224 or 2016 had no calculable heritability. For $\mathrm{Mg}(\mathrm{H}=0.34$; confidence intervals $(\mathrm{CI})$ : 0.18-0.46), B

$225(\mathrm{H}=0.44$; $\mathrm{CI}: 0.32-0.55), \mathrm{K}(\mathrm{H}=0.21$; CI: 0.02-0.36), $\mathrm{Al}(\mathrm{H}=0.12$; $\mathrm{CI}: 0-0.28)$, and $\mathrm{Fe}(\mathrm{H}=$

2260.27 ; CI: $0.10-0.41)$ broad sense heritability was moderate to low.

227

228 Nutrient concentration and symptom correlations

229 Symptoms (marginal chlorosis, stunting or both) were positively correlated with $\mathrm{Na}, \mathrm{Mg}, \mathrm{Fe}$ and

230 Al concentrations, and negatively correlated with $\mathrm{N}$ across both years (Figure 2, Table 4,

231 Supplemental Figure 2). In $2015 \mathrm{Mg}$ concentrations $(\mathrm{r}=0.6146)$ and in $2016 \mathrm{Al}$ concentrations

$232(\mathrm{r}=0.4805)$ had the highest correlation with observed vineyard symptoms (Table 4). Na and Fe

233 concentrations were also correlated with symptoms in both years, though at lower $r$ values. In

234 2015, a significant negative correlation between S concentration (22\%) and symptoms was

235 observed, but not in 2016 (Supplemental Table 2). In 2016, there was a significant negative

236 correlation between $\mathrm{P}, \mathrm{Cu}$, and $\mathrm{K}$ content and symptoms (Supplemental Table 2). Other

237 significant correlations among nutrients included positive correlations $(r \geq 0.30)$ between $\mathrm{N}, \mathrm{P}$,

238 and $\mathrm{S}$ in 2015 and S, P, and $\mathrm{K}$ in 2015 and 2016 (Supplemental Table 2). A strong positive

239 correlation was also detected for both $\mathrm{Mn}$ and $\mathrm{Ca}$ with $\mathrm{Mg}$ in 2015, but not 2016. Correlation 
240 with symptoms were observed for other nutrients, but were not consistent between years. When

241 comparing nutrient concentrations from 2015 to 2016, most nutrients had low to moderate $(\mathrm{r}=$

$2420.2-0.4)$ correlation, with the exception of copper $(\mathrm{r}=-0.0199)$ (Supplemental Table 3).

243 Nutrient ratios were examined between years for potential significant correlations with

244 symptoms. Most ratios did not show consistent differences in values between years for

245 symptomatic and non symptomatic vines (Supplemental Table 4).

246

247 Marker-trait associations

248 Linkage disequilibrium half-decay distance was estimated to be $100 \mathrm{Kbp}$ (Supplemental Figure

249 3). Genome-wide associations identified several chromosomes associated with differences in the 250 ions evaluated (Supplemental Figure 4, Figure 3). Significant positive associations between 251 SNPs on chromosome 3 and Mg concentration were detected in 2015 for both the Thompson 252 Seedless and PN40024 genomes. SNPs associated with Mg levels explained approximately 6\% 253 of trait variation (Supplemental Table 5). In 2015, 6 SNPs were detected when aligned to the 254 PN40024 genome while 4 SNPs were detected when aligned to Thompson Seedless. No SNPs 255 associated with $\mathrm{Mg}$ accumulation were identified in 2016 with either genome at the $P=0.05$ 256 FDR level. Only 1 genic SNPs associated with Mg concentration was identified and was co257 associated with SNPs identified for marginal leaf chlorosis and stunting (Supplemental Tables 6 258 and 7). In the Thompson Seedless genome, a small block of SNPs (S3_21825918, 259 S3_21825925, and S3_21825966), spanning 48 bp, located in a 7,000 bp intra genomic region, 260 explained $\sim 18 \%$ of the variation associated with symptoms in 2015. A BLAST search of the 261 region did not identify any significant alignments with any genes (predicted, putative or known) 262 in Vitis or other species.

263

264 SNPs associated with Na concentration were detected on chromosomes 11, 12, 13, and 18 had 265 both negative and positive allelic effects ranging from 8 to $13 \%$ of the observed variation in the 266 Thompson Seedless genome. Three of the SNPs (S11_16152632, S18_25745134, and 267 S18_25745143) were detected in 2015 and 2016. None of the SNPs associated with Na 268 concentration in 2015 were located in predicted or known genes. Only a single SNP identified in 2692016 (S11_11635675) was found in an annotated gene (Supplemental Table 6). In the PN40024 270 genome, 11 SNPs with positive allelic effects were detected across chromosomes 3, 11, 15, and 
27117 in 2016. Individual SNPs explained 6 to $11 \%$ of the variation observed. Two of the SNPs on

272 chromosomes 3 and 11 were also associated with Na concentrations in 2015, but were not

273 significant when including adjusted for an FDR of 0.05. Using the PN40024 genome annotation,

2748 genes were associated with $\mathrm{Na}$ accumulation. These included genes putatively involved

275 metabolism and transport. Four of the genes had no functional annotation ascribed (Table 5).

276 One gene, Vitvi11g01139, was associated with $\mathrm{Na}$ accumulation and annotated as a Clathrin

277 assembly protein, which is a class of proteins involved in macromolecule transportation. No

278 significant SNPs were identified for any of the remaining ions measured.

279

280 For marginal chlorosis, a total of 151 SNPs, 57 in 2015 and 94 in 2016 were detected across

2812015 and 2016, respectively in the Thompson Seedless genome. In 2015, 33 of the identified

282 SNPs were located in genes, while in 2016, 20 SNPs were located in genes (Table 6). Sixteen of

283 the genic SNPs were shared between years. Individual SNP effects on the Thompson Seedless

284 genome were both negative and positive and ranged from 16 to 33\%. Many of the SNPs

285 identified in only a single year were located in genes with multiple SNPs associated with the trait

286 (Supplemental Table 6). When aligned to the PN40024 genome, a total of 29 and 55 SNPs in

2872015 and 2016, respectively associated with marginal chlorosis were detected. Marginal

288 chlorosis was primarily associated with SNPs on chromosome 3 with other SNPs detected on

289 chromosomes 6, 9, 13, 16, 17 and 19. In 2015, 23 of the identified SNPs were located in genes,

290 while in 2016, 22 SNPs were located in genes, 22 SNPs were shared between years. Similar to

291 the SNPs detected in Thompson Seedless genome, many SNPs were consistent across both years

292 on chromosomes 3 and 16.

293

294 A total of 37 and 71 SNPs associated with stunting were identified in 2015 and 2016,

295 respectively when mapped to the Thompson Seedless genome. SNP effects varied from 3 up to

$29640 \%$. Highest effect SNPs were detected on chromosome 3 with smaller effect SNPs located on

297 chromosomes 18 (2015) and 1, 2, 10, 11, 12, 16 and 18 (2016). Twenty-four and 34 SNPs were

298 associated with genes in 2015 and 2016, respectively. Nineteen of the genic SNPs associated

299 with plant stunting were shared between years. The majority of single-year SNPs were identified

300 in 2016 (Supplemental Table 5). When mapped to the PN40024 genome, a total of 34 and 44

301 SNPs were detected in 2015 and 2016, respectively. Only 34 and 35 SNPs associated with 
302 stunting were located in genes for 2015 and 2016, respectively of which 29 were shared between 3032015 and 2016.

304

305 No ion transport pathways were associated with symptom-associated SNPs based on the

306 Thompson Seedless annotation, however approximately $50 \%$ of the genes had putative catalytic

307 activity and 50\% had binding activity (Supplemental Figure 5). None of the genes identified

308 across both years and associated with symptoms were putative transporters, but were instead

309 involved in processes such as oxidation, transcription, development, and stress response (Table

310 6). When symptom-associated SNPs located in genes based on the PN40024 annotation were

311 evaluated for putative activity, stress response, transcription, growth and development, and

312 metabolic pathways were all represented similar to the Thompson Seedless genome. In addition,

313 SNPs were also detected in several genes related to sugar and nutrient transport. One SNP

314 associated with leaf stunting in both years and symptoms was associated with Calcium ion

315 binding (Vivi03g00243).

316

317 The majority of symptom-associated SNPs were found on chromosome 3 in both genomes, but

318 each genome has a unique coordinate system. Therefore, we performed a consolidated genome

319 analysis by mapping significant SNPs in Thompson seedless and their flanking regions to the

320 PN40024 genome in order to order SNP coordinates and look for overlap between references

321 (Figure 4). When chromosome 3 assemblies were consolidated, a shared cluster of SNPs with

322 significant association with symptoms was observed $\sim 7.5 \mathrm{Mb}$ and a lesser cluster around $\sim 15 \mathrm{Mb}$.

323 When aligned to the Thompson Seedless genome, symptom-associated SNPs located within

324 genes shared across years were predominantly found on chromosome 3 with an additional SNP

325 located on chromosome 10 (Table 6, Supplemental Table 6). Significant single year SNPs,

326 including those associated in genes, were identified on chromosomes 1, 2, 3, 4, 10, 11, 12, 16,

327 and 18 (Supplemental Table 5). When symptoms were combined, 28 SNPs were shared across

328 both years, and 29 were only identified in a single year (Supplemental Table 5). When aligned to

329 the PN40024 genome, significant SNPs were detected on chromosomes 3, 6, 11, 16, and 19.

330 Most of the identified SNPs were located on chromosome 3, and 21 were shared between 2015

331 and 2016 (Table 5). Twenty SNPs were only detected in a single year, with the majority

332 identified in 2016 (15). Twenty-nine SNPs found on chromosome 3 were shared between years 1 
333 and 2. Sixteen genic SNPs associated with the combined symptoms were identified in both 2015 334 and 2016 (Table 5).

\section{Discussion}

Proper macro and micro nutrient accumulation in grapevines is a perennial concern for growers, particularly in regions with marginal soils. Deficiencies, overaccumulations, or mis-partitioning of nutrients can result in economic losses in yield and fruit quality, and occasionally cause plant death. In our study, a heterozygous segregating Vitis vinifera $\mathrm{F}_{1}$ population ('Verdejo’ $\mathrm{x}$

343 'Gewürztraminer'; denoted as VxT) segregating for foliar symptoms was evaluated for micro 344 and macro nutrient and ion (N, S, P, K, Mg, Ca, Na, Fe, Al, Mn, B, Cu, and Zn) concentrations 345 and symptom-associated SNPs. We chose to utilize a GWAS style approach to detect 346 significantly associated SNPs amongst the progeny, similar to work by Zou et al. demonstrating genome-wide marker association with flower sex (2020) rather than pursue a traditional QTL approach. This approach allowed us to evaluate the genetic architecture of leaf symptoms through the high SNP detection produced by using next-generation GBS methods. In the case of $\mathrm{Na}$, this approach enabled the detection of significant SNPs, even when low or no heritability was calculated, likely due to the low $\mathrm{Na}$ concentrations observed $(0.0$ to $0.2 \% \mathrm{dm})$.

Normal nutrient ranges for plants vary depending on environment, variety, maturity, tissue, plant age, and developmental stage making comparisons among studies difficult even when using the same cultivar (Benito et al. 2013; Pradubsuk and Davenport 2010; Conradie 1992; Schreiner et al. 2006; Schreiner 2016). This difficulty is exemplified by the results presented here, where significant changes in ion concentrations varied in the two years of the study. Most ions showed an increase in concentration from 2015 to 2016, with the exception of B, P, N, K despite higher levels being applied in 2016. However, low correlations between years indicated that year $\mathrm{x}$ genotype played a substantial role in ion concentrations. These higher levels of ions in 2016, likely contributed to the increased number of SNPs detected in 2016 compared to 2015. In the

362 VxT population, $\mathrm{P}, \mathrm{B}$, and $\mathrm{Cu}$ concentrations were within previously reported "normal" limits for 363 V. vinifera petioles (Bates and Wolf 2008), had no correlation with observed physiological 
364 symptoms, and low to moderate variability among individuals. All other nutrients or ions

365 evaluated were outside of normal ranges or baseline levels have not been established.

366 Concentrations of $\mathrm{N}, \mathrm{Mg}, \mathrm{Na}, \mathrm{Fe}$, and $\mathrm{Al}$ were outside (higher or lower) of the normal range for

367 grape and were strongly associated with symptoms in both 2015 and 2016. Deficiencies or

368 surplus of several of these ions can result in chlorosis, marginal leaf burn, or stunting. However,

369 the symptoms observed were not consistent with any single nutrient imbalance or "acidic soil

370 sickness", a term used to describe foliar symptoms related to deficiencies in $\mathrm{Ca}, \mathrm{Mg}$, or $\mathrm{P}$ from

371 low $\mathrm{pH}$ soils (Wilcox et al. 2015). This suggests the symptoms in the VxT population were the

372 result of misaccumulation in more than one ion.

373

374 Iron deficiency and aluminum toxicity can result in interveinal chlorosis and necrosis, but not the

375 marginal leaf burn, stunting and chlorosis observed in the VxT population. In our work, strong

376 positive correlations ( $>95 \%$ ) were observed among Fe and Al concentrations in both

377 symptomatic and asymptomatic plants across years. A similar positive correlation was detected

378 in maize, but has not been reported in other crops (Hoffer and Trost 1923). Previous studies have

379 shown that, aluminum tolerance variability exists among grape cultivars, with highly sensitive

380 genotypes showing reduced root growth (Cancado et al. 2009). Conflicting information exists on

381 the effects of aluminum on accumulation and distribution of nutrients in plants. It has been

382 shown that it can negatively impact plant health by restricting the uptake of nutrients

383 predominantly $\mathrm{Ca}$ and $\mathrm{Mg}$ in maize (Mariano and Keltjens 2005). However, other studies on

384 maize have shown that $\mathrm{Mg}$ and $\mathrm{Ca}$ content in the shoots show little variability when exposed to

385 Al in the soil (Lidon et al. 2000; Olivares et al. 2009). In our study, high concentrations of $\mathrm{Mg}$

386 were observed despite the high concentrations of Al also being present.

387

388 In grape, Mg deficiency symptoms are typically interveinal chlorosis starting at the leaf edge.

$389 \mathrm{Mg}$ overaccumulation has not been described in grape, but in other plant species was

390 characterized by stunted growth and foliar yellowing. In our population, marginal, but not

391 interveinal, chlorosis and stunting were observed and positively associated (32-60\%) with an

392 increase in foliar $\mathrm{Mg}$ content. In excess, $\mathrm{Mg}$ can inhibit the absorption of other essential nutrients

393 such as Ca or K affecting root and shoot growth (Kobayashi et al. 2005; Tang et al. 2015;

394 Venkatesan and Jayaganesh, 2010). This was similar to our study, where calcium and manganese 
395 levels decreased while Mg concentration increased in symptomatic plants. SNPs associated with

$396 \mathrm{Mg}$ accumulation were identified on chromosome 3, but none of the genic SNPs were associated

397 with putative transporters and a small 48 bp block of SNPs were not located in a known genic

398 region. A previous study by Mandl et al. (2006) determined that Mg deficiency was associated

399 with a region on chromosome 11. In our work, chromosome 11 was associated with Na, but not

$400 \mathrm{Mg}$ accumulation. These data combined would suggest that Mg accumulation in the VxT

401 population is not a result of an overexpression of a Mg-specific transporter as was postulated by

402 Mandl et al (2006). SNPs associated with foliar symptoms were also predominantly located on

403 chromosome 3, suggesting that $\mathrm{Mg}$ content had a role in the visible symptoms. However, many

404 of the remaining symptom-related SNPs did not overlap with those associated with $\mathrm{Mg}$ content

405 indicating that this is only one small piece of the equation.

406

407 In grape, Na stress symptoms can include internode and leaf stunting, as well as leaf burns 408 (Sinclair and Hoffman, 2003). Leaf chlorosis, observed in our study, is not considered a 409 symptom of salt stress in grape, but $\mathrm{Na}$ levels were consistently associated with symptoms in 410 years 1 and 2 (Baneh et al. 2014). Strong correlations between Na concentrations and those of

$411 \mathrm{Mg}, \mathrm{Ca}$, and $\mathrm{N}$ were observed in the first year of this study, but were not consistent across years. 412

413 In the VxT population, $\mathrm{Na}$ accumulation was found to be associated with SNPs located on 414 chromosome 11 consistent with previous work (Henderson et al., 2017) in addition to 415 chromosomes 3 and 18. Henderson et al. (2017) and Wu et al. (2020) found variability in high 416 affinity potassium transporters (HKT) that could improve exclusion of $\mathrm{Na}$ in grape leaves, using 417 interspecific hybrids from $V$. champinii and $V$. rupestris and later in $V$. vinifera. The SNP 418 identified on chromosome 11 and found in 2015 and 2016 in the PN40024 genome did not co419 localize to regions with known $V v i$ HKT members, and may be a novel modifier of leaf $\mathrm{Na}$ 420 exclusion. In our study, individual SNP (genic and non-genic) effects varied widely. Overlap 421 between $\mathrm{Mg}$ and $\mathrm{Na}$ concentration-associated SNPs and those associated with symptoms 422 (marginal leaf chlorosis, stunting or both) indicate that symptoms were, in part, tied to the 423 accumulation or mispartitioning of both $\mathrm{Mg}$ and $\mathrm{Na}$ in the vine. The effect of individual SNPs 424 varied suggesting that nutrient-related symptoms in this population may be the result of 425 interactions of various ions, particularly $\mathrm{Al}, \mathrm{Na}, \mathrm{Fe}$, and $\mathrm{Mg}$. 
427 Grape has a high level of heterozygosity, and separating genotype errors from minor alleles can 428 be challenging (Hyma et al., 2015). As more grape genomes are sequenced, it is quite apparent 429 that genomic inversions and deletions are common among cultivars and the grapevine gene 430 annotation is constantly being modified. Some of the candidate SNPs identified here may 431 associate with currently unannotated genes not present in the Thompson Seedless or PN40024 432 genomes. Additionally, as 'Geuwurztraminer' is an aromatic sport of 'Traminer', which itself is 433 the parent of 'Verdejo', this population is genetically similar to an $\mathrm{F}_{1}$ back cross $1\left(\mathrm{~F}_{1} \mathrm{BC}_{1}\right)$. The 434 apparent presentation of symptomatic vines in a 3:1 recessive pattern also suggests that both 435 parents may carry associated genes in a heterozygous state that when combined, produce the 436 undesirable trait. Grape is particularly susceptible to inbreeding depression, and these SNPs may 437 be associated with deleterious alleles of regulatory or genic regions not annotated in sequenced 438 grape genomes. While speculative, it is possible that the wide distribution of many SNPs of 439 varying effects across chromosome 3 suggests this chromosome may by carrying deleterious 440 alleles. While multiple SNPs were identified in this study, additional work is needed to confirm 441 their role in nutrient accumulation. When comparing SNP results between the two genomes used 442 in this study, it was clear that chromosome 3 was a major contributor of the phenotypic variation 443 observed in the VxT population. Similarly, individual SNPs identified in both genomes had high 444 variability in effects on symptoms (leaf stunting and/or chlorosis), with few genes having more 445 than one significant SNP. In the Thompson Seedless genome annotation, most $\mathrm{Na}$ associated 446 SNPs were located in large intergenic regions of the genome. Fewer significant SNPs were 447 detected in the PN40024 genome compared to the Thompson Seedless, as was expected due to 448 the increased filtering in the PN40024 genome. However, in Thompson Seedless, multiple SNPs 449 within a single gene were detected, but not for the PN40024 genome suggesting that higher 450 stringencies of filtering could make the dataset more manageable without losing too many 451 regions of interest. The combination of a low read depth threshold and the absence of genetic 452 mapping could result in genotyping errors, which may be a source of error. These data highlight 453 the importance of genome, annotation and filtering, selection when performing these types of 454 studies.

\section{Conclusion}


458 In summary, we evaluated a Vitis vinifera segregating population for micro and macro nutrient

459 accumulation across two years. Broad sense heritability was low for most nutrient concentrations

460 and showed no variability in the population for copper concentration. For nutrients with high

461 variability in the population, this low broad sense heritability is indicative of a large

462 environmental component. This was further evident in that specific nutrient concentrations

463 fluctuated with environmental conditions, vine age or the interaction between environment and 464 individual genotype from 2015 to 2016, though trends were consistent across years. Symptom465 associated genic SNPs identified were located in putative stress response-related genes.

466 However, many SNPs identified were not associated within known genic regions. Many of the 467 SNPs associated with Mg accumulation were distributed across chromosome 3 for both of the 468 genomes evaluated. While it is clear that a block of SNPs on chromosome 3 is affecting this trait,

469 this bi-parental population had insufficient recombination in the region to identify associated 470 candidate genes. SNPs associated with $\mathrm{Na}$ and $\mathrm{Mg}$ accumulation as well as foliar symptoms were 471 identified. However, imbalances in neither of these single ions were able to fully explain the 472 observed symptoms, and the relationship with symptoms varied as the plants aged and other 473 nutrient levels changed. These fluid relationships highlight the complexity of micro- and macro 474 nutrient relationships in perennial crops.

475

476

\section{Acknowledgements}

477

478

The authors would like to thank Elisha Partin and Lindsay Wourms for technical assistance in

479 sample collection and in-field phenotyping. We would like to thank Dr. Konstantin Divilov for assistance with testing BLUPs. Mention of trade names or commercial products in this publication is solely for the purpose of providing specific information and does not imply recommendation or endorsement by the U.S. Department of Agriculture. USDA is an equal opportunity provider and employer. Funding for this project was provided, in part, by E. \& J. 485 Analysis Cores at the UC Davis Genome Center, supported by NIH Shared Instrumentation 486 Grant 1S10OD010786-01.

487

488

\section{References}


490 Arif N, Yadav V, Singh S, Singh S, Ahmad P, Mishra RK, Sharma S, Tripathi DK, Dubey NK, 491 Chauhan DK. 2016. Influence of high and low levels of plant-beneficial heavy metal ions on 492 plant growth and development. Front Environ Sci 21:69.

493

494

495

496

497

498

499

Baneh HD, Hassani A, Shaieste FG. 2014. Effects of salinity on leaf mineral composition and salt injury symptoms of some Iranian wild grapevine (Vitis vinifera L. ssp. sylvestris) genotypes. J Int Sci Wine and Vine 48:1692.

Bates T, Wolf T. 2008. Vineyard Nutrient Management. Wolf T. (eds) In Wine Grape Production for Eastern North America. NRAES, Ithaca NY

500

501

502

503

504

505

506

507

508

509

510

511

512

513

514

515

516

517

Benito A, Romero I, Dominguez N, Garcia-Escudero E, Martin I. 2013. Leaf blad and petiole analysis for nutrient diagnosis in Vitis vinifera L. cv. Garnacha tinta. Aus j Grape Wine Res 19:285-298.

Bernstein L. 1975. Effects of salinity and sodicity on plant growth. Ann. Rev. Phytopath. 13:295-312.

Bert PF, Bordenave L, Donnart M, Hevin C, Ollat N, Decroocq S. 2016. Mapping genetic loci for tolerance to lime-induced iron deficiency chlorosis in grapevine rootstocks (Vitis sp.)

Theo Appl Genet 126:451-473.

Black CA. 1965. Methods of Soil Analysis, Part 2, Chemical and Microbiological Properties, Number 9, $2^{\text {nd }}$ Ed. American Society of Agronomy (ASA) Madison, WI.

Bose J, Babourina 0, Rengel Z. 2011. Role of magnesium in alleviation of aluminum toxicity in plants. J Exp Bot 63:2251-2264.

Bradbury PJ, Zhang Z, Kroon DE, Casstevens TM, Ramdoss Y, Buckler ES. 2007. TASSEL: software for association mapping of complex traits in diverse samples. Bioinformatics 23:2633-2635.

Brancadoro L, Rabotti G, Scienza A, Zocchi G. 1995. Mechansims of Fe-efficiency in roots of Vitis spp. in response to iron deficiency stress. Plant and Soil 2:229-234.

Canaguier A, Grimplet J, Di Gaspero G, Scalabrin S, Duchene E, Choisne N, Mohellibi N, Guichard C, Rombauts S, Le Clainche I, Berard A, Chauveau A, Bounon R, Rustenholz C, MOrgante M, Le Paslier MC, Brunel D, Adam-Blondon AF. 2017. A new version of the grapevine reference genome assembly (12X.v2) and of its annotation (VCost.v3). Genom Data 14:56-62.

530

531 Cancado GMA, Ribeiro AP, Pineros MA, Miyata LY, Alvarenga AA, Villa F, Pasqual M, 532 Purgatto E. 2009. Evaluation of aluminium tolerance in grapevine rootstocks. Vitis 48:167533173.

534 
535 Carbonell-Barrachina AA, Burlo-Carbonell F, Mataix-Beneyto J. 2008. Effect of sodium

536 arsenite and sodium chloride on bean plant nutrition (macronutrients). 20:1617-1633.

537

538

539

Christensen P. 1984. Nutrient level comparisons of leaf petioles and blades in twenty-six grape cultivars over three years (1979 through 1981). Am J Enol Vit 35:124-133.

540

541

542

543

544

545

546

547

548

549

550

551

552

553

554

555

556

557

558

559

560

561

562

563

564

565

566

567

568

569

570

571

Clemens S. 2001. Molecular mechanisms of plant metal tolerance and homeostasis. Planta 212:475-486.

Conradie WJ. 1981. Seasonal uptake of nutrients by Chenin Blanc in sand culture: II.

phosphorous, potassium, calcium and magnesium. S. Afr. J. Enol. Vit 2:7-13.

Conradie WJ. 1992. Partitioning of nitrogen by the grapevine during autumn and the utilization of nitrogen reserves during the following growing season. S African J Enol Vit 13:45-51.

Conradie WJ, Saayman D. 1989. Effects of long-term nitrogen, phosphorus, and potassium fertilization on Chenin Blanc vines. II. Leaf analyses and grape composition. Amer J Enol Vit 40:91-98.

Cordovilla MP, Ocana A, Libero F, Lluch C. 1995. Salinity effects on growth analysis and nutrient composition in four grain legumes - rhizobium symbiosis. J Plant Nut 18:1595 1609.

Danecek P, Auton A, Abecasis G, Albers CA, Banks E, DePristo MA, Handsaker R, Lunter G, Marth G, Sherry ST, McVean G, Durbin R, 1000 Genomes Project Analysis Group. 2011. The variant call format and VCFtools. Bioinformatics. 27:2156-2158.

Davies C, Shin R, Liu W, Thomas MR, Schachtman DP. 2006. Transporters expressed during grape berry (Vitis vinifera L.) development are associated with an increase in berry size and berry potassium accumulation. J Exp Bot 57:3209-3216.

Downton WJS. 1977. Chloride accumulation in different species of grape-vine. Sci Hort 7:249-253.

Fehr WR. 1987. Principles of cultivar development. Macmillan, Inc. New York.

Genova AD, Almeida AM, Munoz-Espinoza C, Vizoso P, Travisany D, Moraga C, Pinto M, Hinrichsen P, Orellana A, Maass A. 2014. Whole genome comparison between table and wine grapes reveals a

572

573

574

575

576

577

578

579 comprehensive catalog of structural variants. BMC Plant Biology 14:7.

Gong HJ, Blackmore DH, Clingeleffer PR, Sykes SR, Walker RR. 2015. Variation for potassium and sodium accumulation in a family from a cross between grapevine rootstocks K 51-40 and 140 Ruggeri. J Grape Res 53:65-72.

Gotz S, Garcia-Gomez JM, Terol J, Williams TD, Nagaraj SH, Nueda MJ, Robles M, Talon M, Dopazo J, Conesa A. 2008. High-throughput functional annotation and data mining with the

580 Blast2GO suite. Nucl Acid Res 36:3420-3435. 
581

582

583

584

585

586

587

588

589

590

591

592

593

594

595

596

597

598

599

600

601

602

603

604

605

606

607

608

609

610

611

612

613

614

615

616

617

618

619

620

621

622

623

624

625

626

Grattan SR, Grieve CM. 1992. Mineral element acquisition and growth response of plants grown in saline environments. Ag Eco Env 38:275-300.

Guo W, Nazim H, Liang Z, Yang D. 2016. Magnesium deficiency in plants: An urgent problem. Crop Journal 4:83-91.

Henderson CR. 1975. Best linear unbiased estimation and prediction under a selection model. Biometrics 31:423-447.

Henderson SW, Dunlevy JD, Wu Y, Blackmore DH, Walker RR, Edwards EJ, Gilliham M, Walker AR. 2017. Functional differences in transport properties of natural HKT1;1 variants influence shoot $\mathrm{Na}+$ exclusion in grapevine rootstocks. New Phyto 217:1113-1127.

Hermans C, Verbruggen N. 2005. Physiological characterization of Mg deficiency in Arabidopsis thaliana. J Exp Bot 56:2153-2161.

Hoffer GN, Trost JF. 1923. The accumulation of iron and aluminum compounds in corn plants and its probable relationship to root rots. II. J Amer Soc Agron 15:323-331.

Hyma KE, Barba P, Wang M, Londo JP, Acharya CB, Mitchell SE, Sun Q, Reisch B, CadleDavidson L. 2015. Heterozygous mapping strategy (HetMappS) for high resolution genotyping-by-sequencing markers: A case study in grapevine. PlosOne e0134880

Hu X, Boyer GL. 1996. Siderophore-mediated aluminum uptake by Bacillus megaterium ATC 19213. Appl Env Micr 62:4044-4048.

Jimenez S, Gogorcena Y, Hevin C, Rombola AD, Ollat N. 2007. Nitrogen nutrition influences some biochemical responses to iron deficiency in tolerant and sensitive genotypes of Vitis. Plant and Soil 290:343-355.

Knapp SJ, Stroup WW, Ross WM. 1985. Exact confidence intervals for heritability on a progeny mean basis. Crop Sci. 25:192-194.

Kobayashi H, Masaoka Y, Sato S. 2005. Effects of excess magnesium on the growth and mineral content of rice and Echinochloa. Plant Prod Sci 8:38-43.

Kocsis L, Walker MA. 2003. Screening Vitis species for use in breeding magnesium tolerant rootstocks. Acta Hort 603:10.17660/ActaHortic.2003.603.52

Li H, Durbin R. 2010. Fast and accurate long-read alignment with Burrows-Wheeler Transform. Bioinformatics, Epub. [PMID: 20080505]

Li H. 2018. Minimap2: pairwise alignment for nucleotide sequences. Bioinformatics, 34:3094-3100. doi:10.1093/bioinformatics/bty191

Peer) reviewing PDF | (2019:08:40548:4:0:NEW 17 Dec 2020) 
627 Lidon FC, Azinheira HG, Barreiro MG. 2000. Aluminum toxicity in maize: biomass

628 production and nutrient uptake and translocation. J Plant Nutr. 23:151-160.

629

630

631

632

633

634

635

636

637

638

639

640

Lipka AE, Tian F, Wang Q, Peiffer J, Li M, Bradbury PJ, Gore MA, Buckler ES, Zhang Z. 2012. GAPIT:

genome association and prediction integrated tool. Bioinformatics 28:2397-2399.

Liu XQ, Rong JY, Liu XY. 2008. Best linear unbiased prediction for linear combinations in general mixed linear models. J of Multivariate Analysis 99:1503-1517.

Ma JF, Chen ZC, Shen RF. 2014. Molecular mechanisms of Al tolerance in gramineous plants. Plant and Soil 381:1-12.

Maathius FJM. 2009. Physiological functions of mineral macronutrients. Curr Op Plant Bio $12: 250-258$.

641

642

Maathuis FJM. 2013. Sodium in plants: perception, signaling, and regulation of sodium

643

644

645 fluxes. J Exp Bot 65:849-858.

646

647

Mandl K, Santiago JL, Hack R, Fardossi A, Regner F. 2006. A genetic map of Welschriesling x Sirius for the identification of magnesium-deficiency by QTL analysis. Euphytica 149:133-

648

649

650

651

652

653

654

655

656

657

658

659 144.

Mariano ED, Keltjens WG. 2005. Long-term effects of aluminum exposure on nutrient uptake by maize genotypes differing in aluminum resistance. J Plant Nut 28:323-333.

Merk HL. 2011. Estimating heritability and BLUPs for traits using tomato phenotypic data. https://plant-breeding-genomics.extension.org/estimating-heritability-and-blups-fortraits-using-tomato-phenotypic-data/

Mohammadkhani N, Abbaspour N. 2015. Salinity effects on potassium accumulation and transporters expression in grape (Vitis vinifera). Iran J Plant Phys 5:1483-1494.

Morris JR, Sims CA, Cawthon DL. 1983. Effects of excessive potassium levels on pH, acidity,

660

661

662

663

664

665

666

667

668

and color of fresh and stored grape juice. Am J Enol Vit 34:35-39.

Mossor-Pietraszewska T. 2001. Effect of aluminum on plant growth and metabolism. Acta Biochimica Polonica 48:673-686.

Mpelasoka BS, Schachtman DP, Treeby MT, Thomas MR. 2003. A review of potassium nutrition in grapevines with special emphasis on berry accumulation. Aus J Grape Wine Res 9:154-168.

669

670

Naranjo-Arcos MA, Maurer F, Meiser J, Pateyron S, Fink-Straube C, Bauer P. 2017.

Dissection of iron signaling and iron accumulation by overexpression of subgroup Ib bHLH039 protein. Sci Reports 7:10911.

671 
672 Olivares E, Pena E, Marcano E, Mostacero J, Aguiar G, Benitez M, Rengifo E. 2009. Aluminum 673 accumulation and its relationship with mineral plant nutrients in 12 pteridophytes from

674 Venezuela. Environ Exp Bot 65:132-141.

675

Patel S, Lu Z, Jin X, Swaminathan P, Zeng E, Fennell AY. 2018. Comparison of three assembly strategies for a heterozygous seedless grape genome assembly. BMC Genomics 19:57.

678

679

Perez-Castro R, Kasai K, Gainza-Cortes F, Ruiz-Lara S, Casaretto JA, Pena-Cortes H, Tapia J,

680

681

682

683

684

685 Fujiwara T, Gonzalez E. 2012. VvBOR1, the grapevine ortholog of AtBOR1, encodes an efflux boron transporter that is differentially expressed throughout reproductive development of Vitis vinifera L. Plant and Cell Phys. 53:485-494.

Poor D, Pedo S, Bertoldi D, Bortolotti L, Failla O, Zamboni M. 2013. Evaluation of new rootstocks for grapevine: nutritional aspects. Proc VIIth IS Min. Nut. Fruit Crop Eds.:

686

687

688

689

690

691

692

693

694

695

696

697 Poovarodom and Yingjajaval S. Acta Hort. 984, ISHS.

Pradubsuk S, Davenport JR. 2010. Seasonal uptake and partitioning of macronutrients in mature 'Concord' grape. J Amer Soc Hort 135:474-483.

Primikiros NI, Roubelakis-Angelakis KA. 2001. Indications for post-translational regulation of Vitis vinifera L., arginine decarboxylase. Plant Molec Biol 45:669-678.

R Core Development Team. 2017. R Foundation for Statistical Computing Vienna, Austria. https://www.R-project.org/

698

699

700

701

702

703

704

705

706

707

708

709

710

711

712

713

714

715

716

717

Rashad RT, Hussein RA. 2014. A comparison study on the effect of some growth regulators on the nutrients content of maize plant under salinity conditions. Ann Ag Sci 59:89-94.

Rogier SY, Keller M, Holzapfel BP, Virgona JM. 2000. Accumulation of potassium and calcium by ripening berries on field vines of Vitis vinifera (L) cv. Shiraz. Aus J Grape Wine Res 6:240-243.

Schreiner RP, Scagel CF, Baham J. 2006. Nutrient uptake and distribution in a mature 'noir' vineyard. HortSci 41:336-345.

Schreiner RP. 2016. Nutrient uptake and distribution in young Pinot noir grapevines over two seasons. Amer Soc. Enol Vit 67:436-448.

Shani U, Ben-Gal A. 2005. Long-term response of grapevines to salinity: Osmotic effects and ion toxicity. Am J Enol Vitic 56:148-154.

Shaul 0. 2002. Magnesium transport and function in plants: the tip of the iceberg. BioMetals 15:309-323.

Shikhamany SD, Chititrai CR, Chadha KL. 1988. Effect of varying levels of nitrogen and potash on petiole nutrient concents in Thompson Seedless grape (Vitis vinifera L.) 
718

719

720

721

722

723

724

725

726

727

728

729

730

731

732

733

734

735

736

737

738

739

740

741

742

743

744

745

746

747

748

749

750

751

752

753

754

755

756

757

758

759

760

761

Sinclair C, Hoffman AA. 2003. Monitoring salt stress in grapevines: are measures of plant trait variability useful? J Appl Ecol 40:928-937.

Skinner PW, Matthews MA. 1990. A novel interaction of magnesium translocation with the supply of phosphorous to roots of grapevine (Vitis vinifera L.) Plant Cell Env 13:821-826.

Spiers JM, Braswell JH. 1994. 793 PB 039 Calcium, magnesium, and nitrogen fertilization affects leaf nutrient content and growth of 'Sterling' muscadine grape. HortSci 29:546.

Tagliavini M, Romboloa D. 2001. Iron deficiency and chlorosis in orchard and vineyard ecosystems. E J Ag 15:71-92.

Tang RJ, Zhao FG, Garcia VJ, Kleist TJ, Yang L, Zhang HX, Luan S. 2010. Tonoplast CBL-CIPK calcium signaling network regulates magnesium homeostasis in Arabidopsis. PNAS 112:3134-3139.

Tavakkoli E, Rengasamy P, McDonald GK. 2010. High concentrations of $\mathrm{Na}+$ and Cl- ions in soil solution have simultaneous detrimental effects on growth of faba bean under salinity stress. J Exp Bot 61:4449-4459.

Thenabadu MW. 1968. Magnesium-sodium interactions effecting the uptake and distribution of potassium and calcium by cotton. Plant and Soil 29:132-143.

Venkatesan S, Jayaganesh S. 2010. Characterization of magnesium toxicity, its influence on amino acid synthesis pathway and biochemical parameters of tea. Res J Phytochem 4:6777.

Verbruggen N, Hermans C. 2013. Physiological and molecular responses to magnesium nutritional imbalance in plants. Plant and Soil 368:87-99.

Volkmar KM, Hu Y, and Steppuhn H. 1998. Physiological responses of plants to salinity: A review. Can J Plant Sci 78:19-27.

Wang D, Karle R, Iezzoni AF. 2000. QTL analysis of flower and fruit traits in sour cherry. Theor Appl Gent 100:535-544.

Wilcox WF, Gubler WD, and Uyemoto JK. 2015. Compendium of grape diseases, disorders, and pests. $2^{\text {nd }}$ Ed. Pp.159-167. APS Press St. Paul, MN.

Williams CMJ, Maier NA, Bartlett L. 2004. Effect of molybdenum foliar sprays on yield, berry size, seed formation, and petiolar nutrient composition of "Merlot" grapevines. J Plant Nut 27:1891-1916

Peer) reviewing PDF | (2019:08:40548:4:0:NEW 17 Dec 2020) 
762 Wu Y, Henderson SW, Wege S, Zheng F, Walker AR, Walker RR, Giliham M. 2020. The 763 grapevine $\mathrm{NaE}$ sodium exclusion locus encodes sodium transporters with diverse transport 764 properties and localization. J Plant Phys. 246-247.

765

766 Zhang Z. 2016. GAPIT version 2: an enhanced integrated tool for genomic association and 767 prediction. Plant Genome 9:2

768

769

770

771

772

773

774 775

Zhang C, Dong SS, Xu JY, He WM, Yang TL. 2019. PopLDdecay: a fast effective tool for linkage disequilibrium decay analysis based on variant call format files. Bioinformatics 35:1786-1788.

Zhu JK, Liu J, Xiong L. 1998. Genetic analysis of salt tolerance in Arabidopsis: Evidence for a critical role of potassium nutrition. Plant Cell. 10:1181-1191.

779 transferability in a diverse genus. Nature Communicaions 11:413. 


\section{Table $\mathbf{1}$ (on next page)}

SNP distribution across chromosomes 
1 Table 1. Single Nucleotide Polymorphism distribution across the Thompson Seedless and

2 PN40024 reference genomes.

\begin{tabular}{ccc}
\hline Chromosome & \multicolumn{2}{c}{ Number of SNPs } \\
\hline 1 & Thompson Seedless & PN40024 \\
2 & 608 & 189 \\
3 & 271 & 107 \\
4 & 385 & 180 \\
5 & 543 & 225 \\
6 & 746 & 322 \\
7 & 479 & 207 \\
8 & 663 & 240 \\
9 & 640 & 260 \\
10 & 476 & 214 \\
11 & 676 & 253 \\
12 & 279 & 113 \\
13 & 624 & 257 \\
14 & 609 & 241 \\
15 & 753 & 278 \\
16 & 436 & 137 \\
17 & 418 & 180 \\
18 & 463 & 172 \\
19 & 655 & 283 \\
Total & 398 & 139 \\
\hline & $\mathbf{1 0 , 1 2 2}$ & $\mathbf{3 , 9 9 7}$ \\
\hline
\end{tabular}

3

4 
Table 2 (on next page)

Mean nutrient concentrations by year 
1 Table 2. Mean nutrient concentrations from combined leaf and petiole samples collected in 2015

2 and 2016 from an $\mathrm{F}_{1}$ Vitis population.

\begin{tabular}{cccccc}
\hline Nutrient & Unit $^{\mathbf{A}}$ & \multicolumn{2}{c}{ Population Mean \pm (StD) } & Normal range ${ }^{\mathbf{B}}$ \\
& & $\mathbf{2 0 1 5}$ & & $\mathbf{2 0 1 6}$ & (petioles) \\
$\mathrm{N}$ & $\% \mathrm{dm}$ & $2.19 \pm 0.25^{*}$ & & $1.62 \pm 0.26$ & $0.8-1.2$ \\
$\mathrm{~S}$ & $\% \mathrm{dm}$ & $0.18 \pm 0.02^{*}$ & & $0.17 \pm 0.03$ & - \\
$\mathrm{P}$ & $\% \mathrm{dm}$ & $0.17 \pm 0.03^{*}$ & & $0.13 \pm 0.03$ & $0.14-0.30$ \\
$\mathrm{~K}$ & $\% \mathrm{dm}$ & $0.94 \pm 0.24^{*}$ & & $0.70 \pm 0.24$ & $1.2-2.0$ \\
$\mathrm{Mg}$ & $\% \mathrm{dm}$ & $0.69 \pm 0.17^{*}$ & & $0.83 \pm 0.15$ & $0.35-0.75$ \\
$\mathrm{Ca}$ & $\% \mathrm{dm}$ & $2.44 \pm 0.44^{*}$ & & $3.27 \pm 0.56$ & $1-2$ \\
$\mathrm{Na}$ & $\% \mathrm{dm}$ & $0.02 \pm 0.02^{*}$ & & $0.05 \pm 0.03$ & - \\
$\mathrm{Fe}$ & $\mathrm{ppm}$ & $400.41 \pm 86.27^{*}$ & & $484.20 \pm 175.14$ & $30-100$ \\
$\mathrm{Al}$ & $\mathrm{ppm}$ & $238.05 \pm 57.14^{*}$ & & $315.67 \pm 112.02$ & - \\
$\mathrm{Mn}$ & $\mathrm{ppm}$ & $59.31 \pm 13.08^{*}$ & & $69.53 \pm 18.69$ & $100-1000$ \\
$\mathrm{~B}$ & $\mathrm{ppm}$ & $50.81 \pm 14.60^{*}$ & & $42.00 \pm 16.02$ & $25-50$ \\
$\mathrm{Cu}$ & $\mathrm{ppm}$ & $6.20 \pm 2.43$ & & $6.12 \pm 1.25$ & $5-15$ \\
$\mathrm{Zn}$ & $\mathrm{ppm}$ & $20.78 \pm 3.95^{*}$ & & $26.12 \pm 5.88$ & $30-60$
\end{tabular}

$3 \overline{\mathrm{A}}$ Units of measurement for each micro or macronutrient analyzed as percent dry matter $(\% \mathrm{dm})$

4 or parts per million (ppm).

5 B Typical range for petiole concentrations for Vitis cultivars selected from Bates and Wolf 6 (2008).

$7 *$ indicates a significant difference $(\mathrm{P} \leq 0.05)$ in concentration between 2015 and 2016. 
Table 3 (on next page)

Population mean nutrient concentrations 
1 Table 3. Population means for grapevine nutrient concentrations

\begin{tabular}{lccccc}
\hline Ion & Unit $^{\mathbf{A}}$ & \multicolumn{2}{c}{$\mathbf{2 0 1 5}$} & \multicolumn{2}{c}{$\mathbf{2 0 1 6}$} \\
\hline & & No Sym $^{\mathrm{B}}$ & Symp & No Symp & Symp \\
\cline { 3 - 6 } $\mathrm{N}$ & $\% \mathrm{dm}$ & $2.22 \pm 0.23^{*}$ & $2.09 \pm 0.27$ & $1.63 \pm 0.26^{*}$ & $1.53 \pm 0.22$ \\
$\mathrm{~S}$ & $\% \mathrm{dm}$ & $0.18 \pm 0.02^{*}$ & $0.17 \pm 0.02$ & $0.17 \pm 0.03$ & $0.17 \pm 0.02$ \\
$\mathrm{P}$ & $\% \mathrm{dm}$ & $0.17 \pm 0.03$ & $0.17 \pm 0.02$ & $0.13 \pm 0.03^{*}$ & $0.15 \pm 0.03$ \\
$\mathrm{~K}$ & $\% \mathrm{dm}$ & $0.93 \pm 0.24$ & $0.96 \pm 0.25$ & $0.66 \pm 0.23^{*}$ & $0.86 \pm 0.26$ \\
$\mathrm{Mg}$ & $\% \mathrm{dm}$ & $0.63 \pm 0.11^{*}$ & $0.89 \pm 0.19$ & $0.80 \pm 0.14^{*}$ & $0.95 \pm 0.14$ \\
$\mathrm{Ca}$ & $\% \mathrm{dm}$ & $2.44 \pm 0.43$ & $2.45 \pm 0.44$ & $3.37 \pm 0.54^{*}$ & $2.86 \pm 0.45$ \\
$\mathrm{Na}$ & $\% \mathrm{dm}$ & $0.02 \pm 0.02^{*}$ & $0.03 \pm 0.02$ & $0.04 \pm 0.02^{*}$ & $0.06 \pm 0.05$ \\
$\mathrm{Fe}$ & $\mathrm{ppm}$ & $389.85 \pm 84.44^{*}$ & $431.57 \pm 85.68$ & $443.28 \pm 139.08^{*}$ & $660.06 \pm 205.68$ \\
$\mathrm{Al}$ & $\mathrm{ppm}$ & $230.19 \pm 55.58^{*}$ & $261.25 \pm 55.76$ & $289.02 \pm 89.17^{*}$ & $430.21 \pm 128.03$ \\
$\mathrm{Mn}$ & $\mathrm{ppm}$ & $58.61 \pm 12.69$ & $61.35 \pm 14.15$ & $70.70 \pm 19.17^{*}$ & $64.49 \pm 15.63$ \\
$\mathrm{~B}$ & $\mathrm{ppm}$ & $50.40 \pm 14.39$ & $52.02 \pm 15.24$ & $41.46 \pm 16.61$ & $44.34 \pm 13.07$ \\
$\mathrm{Cu}$ & $\mathrm{ppm}$ & $6.17 \pm 2.60$ & $6.32 \pm 1.87$ & $5.95 \pm 1.20^{*}$ & $6.85 \pm 1.20$ \\
$\mathrm{Zn}$ & $\mathrm{ppm}$ & $20.96 \pm 3.90$ & $20.25 \pm 4.08$ & $25.77 \pm 5.20$ & $27.62 \pm 8.11$
\end{tabular}

2 A Units of measurement for each micro or macronutrient analyzed as percent dry matter (\% dm)

3 or parts per million (ppm).

$4 \quad$ B Non symptomatic (No sym) and Symptomatic (Symp) plants.

$5 *$ indicates a significant difference between symptomatic and asymptomatic plants 
Table 4 (on next page)

Pearson correlations of nutrients 
1

2 Table 4. Correlation (r) among nutrient concentrations in 2015 (gray) and 2016 (white) from 3 grape vines.

\begin{tabular}{|c|c|c|c|c|c|c|c|}
\hline & Mg & $\mathbf{C a}$ & $\mathbf{N a}$ & $\mathbf{F e}$ & Al & $\mathbf{N}$ & Sym $^{A}$ \\
\hline Mg & - & $0.4414 * * *$ & $0.3175 * * *$ & $0.1663 * *$ & $0.2220 * *$ & $-0.3552 * * *$ & $0.6146^{* * *}$ \\
\hline $\mathbf{C a}$ & $0.4123 * * *$ & - & $0.1414^{*}$ & NS & NS & $-0.3394 * * *$ & NS \\
\hline $\mathbf{N a}$ & $0.2134 * *$ & NS & - & $0.1847^{*}$ & $0.1601 *$ & NS & $0.2973 * * *$ \\
\hline $\mathbf{F e}$ & $\mathrm{NS}$ & $-0.2168 * *$ & $0.1850 *$ & - & $0.9675 * * *$ & $-0.1512 *$ & $0.2149 * *$ \\
\hline Al & $0.1385^{*}$ & $-0.1958 *$ & $0.1919 *$ & $0.9841 * * *$ & - & $-0.2290 * *$ & $0.2406 * *$ \\
\hline $\mathbf{N}$ & $-0.2852 *$ & $-0.2822 * * *$ & NS & NS & NS & - & $-0.2275 * *$ \\
\hline Sym & $0.3200 * * *$ & $-0.3619 * * *$ & $0.2436 * * *$ & $0.4724 * * *$ & $0.4805 * * *$ & $-0.1679 *$ & - \\
\hline
\end{tabular}

$\begin{array}{ll}4 & \text { A Symptoms } \\ 5 & * \mathrm{P} \leq 0.05 \\ 6 & * * \mathrm{P}<0.001 \\ 7 & * * * \mathrm{P}<0.0001 \\ 8 & \mathrm{NS}=\text { not significant }\end{array}$




\section{Table 5 (on next page)}

Significant SNPs in genes PN40024 
1 Table 5. Genic Single Nucleotide Polymorphisms (SNPs) associated with symptoms (marginal 2 leaf chlorosis and stunting) using the PN40024 genome annotation and NCBI in 2015 and 2016 3 in an $\mathrm{F}_{1}$ population of $V$. vinifera.

4

\begin{tabular}{lllll}
\hline Chr $^{\mathbf{A}}$ & Gene $^{\mathbf{B}}$ & SNP & Effect $^{\mathbf{C}}$ & Putative function $^{\mathbf{D}}$ \\
\hline 3 & Vitvi03g00380 & S3_4196400 & $23-25 \%$ & Unknown \\
& Vitvi03g01518 & S3_4201002 & $(-) 25 \%$ & PREDICTED: uncharacterized protein \\
& Vitvi03g00384 & S3_4208958 & $21-25 \%$ & Integral membrane protein \\
& Vitvi03g00384 & S3_4209015 & $21-25 \%$ & Integral membrane protein \\
& Vitvi03g00430 & S3_4637832 & $(-) 23-$ & Dof zinc finger protein DOF5.8 \\
& Vitvi03g00520 & S3_5653914 & $24-27 \%$ & Basic helix-loop-helix (bHLH) family \\
Vitvi03g00534 & S3_5852953 & $23-24 \%$ & ABA-specific glucosyltransferase \\
& Vitvi03g00543 & S3_5986778 & $(-) 26-$ & DNA-directed RNA polymerase II \\
Vitvi03g00560 & S3_6167883 & $29 \%-31 \%$ & UNC-50 \\
Vitvi03g00583 & S3_655413 & $(-) 23 \%$ & TIP41 \\
Vitvi03g00603 & S3_6823070 & $29-32 \%$ & R protein MLA10 \\
Vitvi03g00688 & S3_7815436 & $33 \%$ & Hypothetical protein \\
Vitvi03g00688 & S3_7815488 & $(-) 33 \%$ & \\
Vitvi03g00777 & S3_9374358 & $25-29 \%$ & EMB2758 (embryo defective 2758) \\
Vitvi03g01012 & S3_14786293 & $(-) 29 \%$ & No hit \\
Vitvi03g01792 & S3_16473090 & $(-) 26-$ & Peru 1 \\
\hline
\end{tabular}

5 A Chromosome

6 B Putative grape gene based on the PN40024 v2 genome (Canaguier et al., 2017).

$7 \quad$ C Percent of the variation explained by a SNP.

8 D Functional annotation based on PN40024 genome v3 annotation (Canaguier et al., 2017). 
Table 6(on next page)

Significant SNPs in genes 
1 Table 6. Genic Single Nucleotide Polymorphisms (SNPs) associated with symptoms using the

2 Thompson Sdls genome annotation in 2015 and 2016 in an $\mathrm{F}_{1}$ population of $V$. vinifera.

\begin{tabular}{|c|c|c|c|c|}
\hline Chr $^{A}$ & Gene $^{B}$ & SNP & Effect $^{\mathrm{C}}$ & Putative function $D$ \\
\hline 10 & g1087 & S10_19692199 & $6-9 \%$ & Polyphenol oxidase \\
\hline \multirow[t]{27}{*}{3} & g1405 & S3_149721 & $9 \%$ & Probable beta-D-xylosidase 5 \\
\hline & g1407 & S3_265316 & $5-6 \%$ & Uncharacterized protein LOC109124260 \\
\hline & g1462 & S3_921272 & $6-7 \%$ & FAD-linked sulfhydryl oxidase ERV1 \\
\hline & g1519 & S3_2023880 & $5 \%$ & HTH-type transcript regulator protein ptxE \\
\hline & g1523 & S3_2032939 & $4-5 \%$ & CASP-like protein $5 \mathrm{C} 1$ \\
\hline & & S3_2032882 & $4-6 \%$ & \\
\hline & g1599 & S3_2800042 & $6 \%$ & Glycoside hydrolase, family 10 \\
\hline & g1629 & S3_3258173 & $6-9 \%$ & At4g33990 \\
\hline & g1632 & S3_3366650 & $7-9 \%$ & Oxysterol-binding protein 5 \\
\hline & & S3_3366649 & $5-7 \%$ & \\
\hline & g1658 & S3_3935538 & $7-9 \%$ & Polyphenol oxidase \\
\hline & g1676 & S3_4305461 & $5 \%$ & Myb-binding protein $1 \mathrm{~A}$ \\
\hline & g1689 & S3_4773185 & $5 \%$ & Scopoletin glucosyltransferase-like \\
\hline & g1736 & S3_5569343 & $7 \%$ & Receptor-like protein kinase HAIKU2 \\
\hline & g1784 & S3_6826327 & $5-7 \%$ & Os01g0234100-like isoform X1 \\
\hline & g1882 & S3_8415245 & $4-6 \%$ & Classical arabinogalactan protein 9 \\
\hline & g1999 & S3_10174220 & $4-6 \%$ & Dof zinc finger protein DOF3.4-like \\
\hline & g2046 & S3_11599143 & $7-8 \%$ & CSC1-like protein HYP1 isoform X1 \\
\hline & g2086 & S3_12359712 & $7 \%$ & Protein unc-50 homolog \\
\hline & g2129 & S3_13316810 & $5-6 \%$ & Serine/threonine-protein kinase BLUS1 like \\
\hline & g2137 & S3_13577682 & $6-7 \%$ & Exocyst complex component SEC6 \\
\hline & g2185 & S3_14537967 & $7 \%$ & Hypothetical protein VITISV_042288 \\
\hline & g2192 & S3_14638969 & $5-6 \%$ & E3 ubiquitin-protein ligase MBR2 iso $\mathrm{X} 1$ \\
\hline & g2217 & S3_15151065 & $9-10 \%$ & Mitochondrial Rho GTPase 1-like \\
\hline & g2363 & S3_18838966 & $5-7 \%$ & DNA-directed RNA poly II, IV, V sub 3 \\
\hline & $\mathrm{g} 2581$ & S3_22457867 & $6-7 \%$ & D-3-phosphoglycerate dehydrogenase 1 like \\
\hline & g2622 & S3_23241926 & $6 \%$ & $\mathrm{KH}$ domain-containing protein HEN4 \\
\hline
\end{tabular}


3 A Chromosome

4 B Putative grape gene based on the Thompson Seedless genome (Patel et al., 2018).

5 C Percent of the variation explained by a SNP.

6 D Putative function based on BLAST2GO annotation (Gotz et al., 2008).

7 


\section{Figure 1}

Figure 1 - Leaves

Figure 1. (A) Asymptomatic and (B) symptomatic (stunted) grape stem internodes and (C-D) leaves from an F1 V. vinifera population. E. Asymptomatic and symptomatic (marginal leaf chlorosis and stunted) leaves.

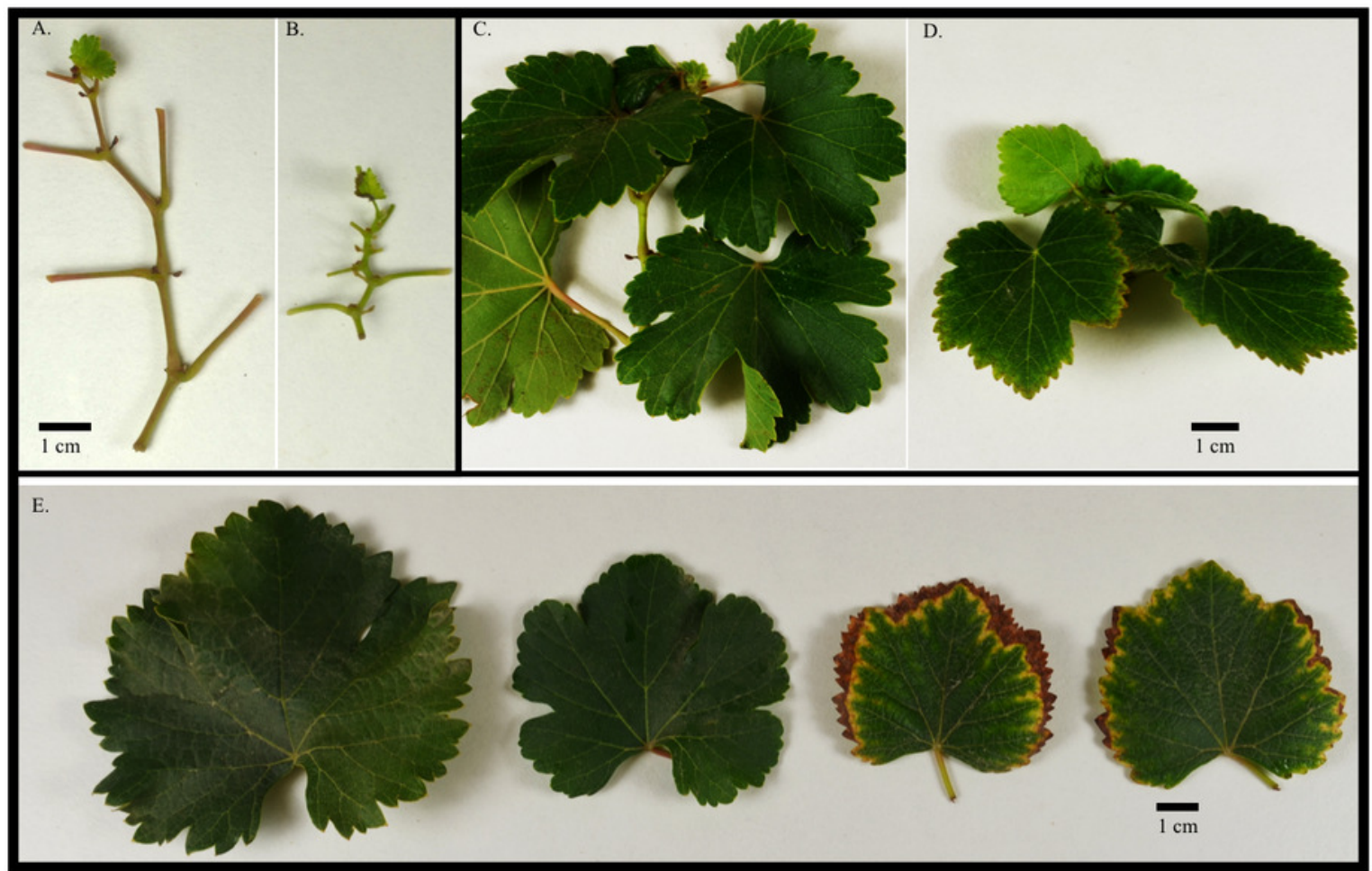




\section{Figure 2}

Figure 2 - PCA

Figure 2. Principal Component Analysis (PCA) based on mean Best Linear Unbiased Predictors (BLUPs) for nutrient concentrations of magnesium (Mg), sodium ( $\mathrm{Na})$, aluminum (Al), iron $(\mathrm{Fe})$, potassium $(\mathrm{K})$, phosphorous $(\mathrm{P})$, nitrogen $(\mathrm{N})$, sulfur $(\mathrm{S})$, zinc $(\mathrm{Zn})$, boron $(\mathrm{B})$, and calcium (Ca). A. Black circles represent non symptomatic plants, blue diamonds indicate plants that exhibited symptoms (only marginal leaf chlorosis (MC) or stunting (SL)) in only one year, teal triangles indicate plants that had symptoms (MC and SL) in only one year, black asterisks represent plants that had SL or MC for both years, and pink squares indicate vines with stunting and leaf chlorosis in both years. B. Vectors for each nutrient based on BLUPS.
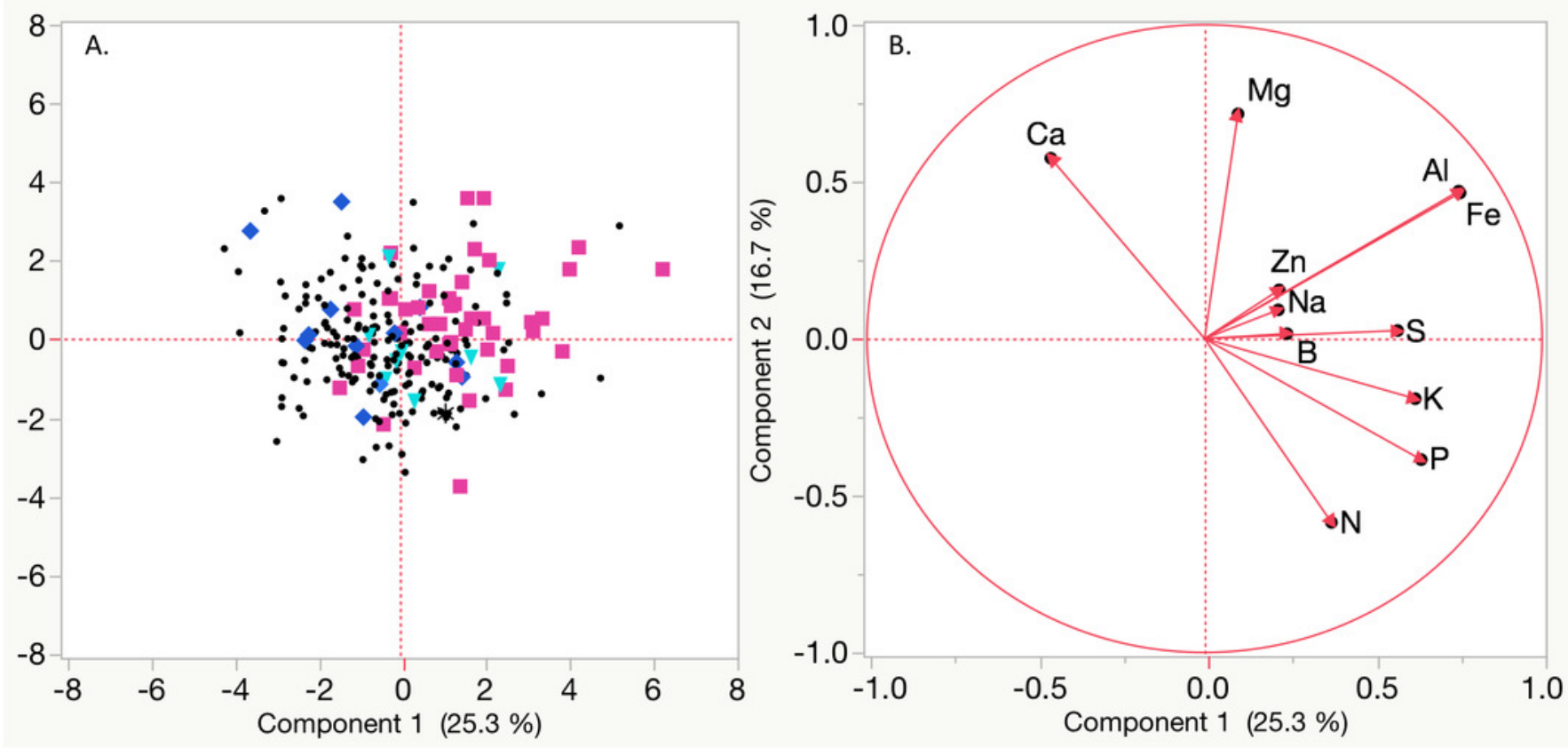
Figure 3

Figure 3 - manhattan plot

Figure 3. Manhattan plot of Single Nucleotide Polymorphisms (SNPs) associated with marginal leaf chlorosis/burn and stunting symptoms in a $V$. vinifera $F_{1}$ segregating population in $A$. 2015 and B. 2016 aligned to the PN40024 genome. The green horizontal line denotes the genome-wide significance threshold at $P<1.0 \times 10^{-6}$.

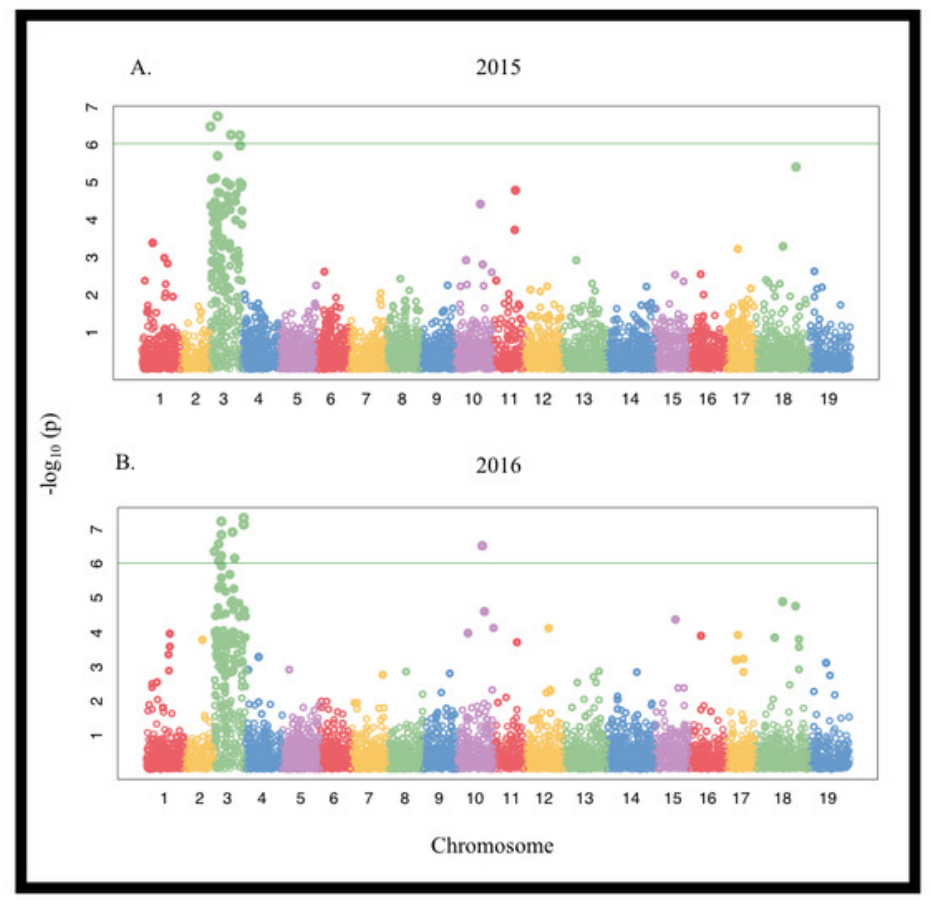




\section{Figure 4}

Fig4 - chromosome structure comparison

Figure 4. Coordinate comparison of the distribution of non significant and significant SNPS identified on chromosome 3 between Thompson Seedless (TS) and PN400424 (PN) reference genomes. The dotted line denotes significance at $P=0.05$.
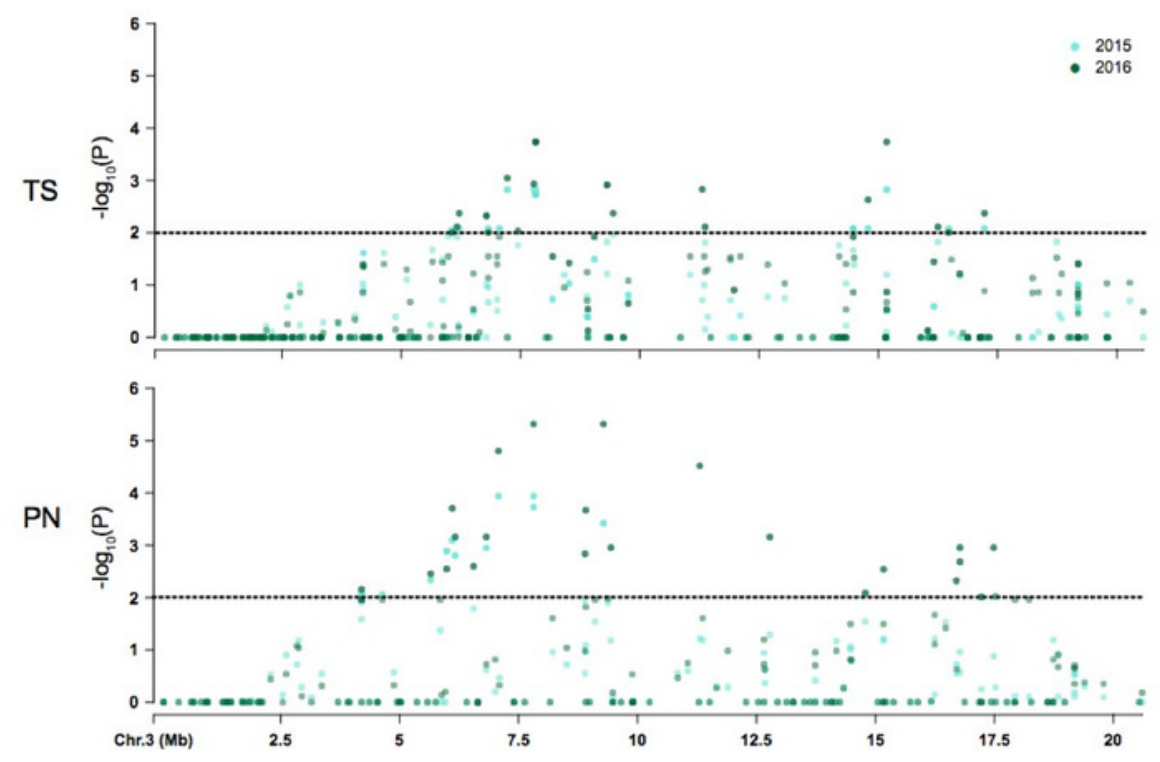